\title{
The Impact of Water Loss by Evaporation and Calcite Precipitation on the Sodium Adsorption Ratio (SAR) and an Alternative Method of Estimating the SAR of Irrigation Drainage Water
}

\author{
Qiyu Zhou ${ }^{\mathrm{a}}$, Douglas J. Soldat ${ }^{\mathrm{a}}$, William F. Bleam ${ }^{\mathrm{a}}$

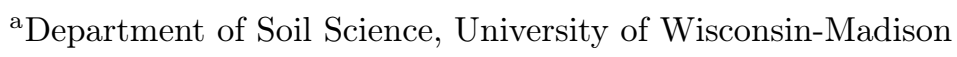 \\ Madison, WI 53706, USA
}

Corresponding author: Qiyu Zhou (Email address: qzhou53@wisc.edu)

\section{Abstract}

Soil water loss by evaporation influences the sodium adsorption ratio (SAR) of irrigation drainage water. Evaporation concentrates sodium and magnesium but calcite precipitation has a more complicated effect on soluble calcium and alkalinity. Here we propose a revised sodicity hazard assessment that quantifies the impact of evaporative water loss and calcite precipitation on drainage water SAR. This paper shows sodicity hazard is determined by the initial composition of irrigation water as originally suggested by previous researchers, and provide a simple, accurate way to identify the potential sodicity hazard of any irrigation water. In particular, the initial equivalent concentration of alkalinity and calcium determine the salinization pathway followed during evaporation. If the irrigation water alkalinity exceeds soluble calcium expressed as equivalent concentrations, drainage water SAR approaches an upper limit determined by the initial relative concentration of sodium and magnesium. If irrigation water alkalinity is less than soluble calcium, drainage water SAR approaches a lower limit determined by the initial calcium, magnesium and sodium. In both cases the SAR is scaled by the square root of the concentration factor $\sqrt{F_{c}}$ quantifying soil water loss.

To assess the impact of evaporation and calcite precipitation on the SAR and test the accuracy of the new sodicity hazard assessment, we evaluated data from 
previously published lysimeter studies. We plotted water composition boundaries for each source water, comparing these boundaries to the drainage water composition recorded in the lysimeter studies. As salinity increased by evaporation, each drainage water followed a distinct salinization path.

KEYWORDS: sodium adsorption ratio, SAR, CROSS, electrical conductivity, specific conductivity, salinity, irrigation, groundwater, water quality

\section{Introduction}

Global agricultural demand for water is steadily growing, driven by population growth and the need to sustain food production. Climate change adds uncertainty to agricultural water demand. Warming will extend growing seasons in temperate climate zones and future trends in annual and seasonal precipitation throughout the world remain unknown.

As water demand exceeds supply, water managers, of necessity, will reduce allocations or draw on lower quality sources to meet demand. Expanding the water-resource portfolio by adding lower quality water sources will reduce agricultural resilience, adding further uncertainty to an already clouded future.

Sustainable irrigation in arid and semi-arid climate zones relies on soil salinity management. Root zone salinity is managed by applying water in excess of crop demand to leach accumulating salts from the soil profile. These salts derive from the applied water, concentrated by crop water loss. Efficient and effective salinity management must maintain infiltration at the soil surface and hydraulic conductivity through the soil profile.

Irrigation managers can easily predict the leaching ratio needed to maintain soil salinity at crop tolerable levels but cannot easily predict changes in solute composition accompanying salinization. Salinization triggers calcite precipitation which removes calcium and alkalinity from solution, altering the relative proportions of soluble major cations and, through cation exchange, the relative proportions of exchangeable major cations.

\subsection{Irrigation Water Quality Parameters}

The most commonly used irrigation water quality parameters (Table 1) rely on soluble major cations. The changes in soluble ion composition during salinization, however, result almost entirely from calcite precipitation and, therefore, depend on the alkalinity-to-calcium ratio in solution.

All parameters appearing in Table 1 are based solely on source water composition and provide no clue how they will change as minerals such as calcite and gypsum precipitate during salinization. Eaton [3], by introducing the largely ignored soluble sodium percent (possible) (1), made the first attempt to predict the effect of calcite precipitation on drainage water composition as soil water-loss drives salinization. Expression (1) is conditional because the residual sodium carbonate $\mathrm{RSC}$ is undefined if $(\mathrm{Ca}+\mathrm{Mg})>\mathrm{HCO}_{3}$. 
Table 1: Water quality parameters routinely used to assess water quality for irrigation and rate sodium hazard. All ion concentrations are denoted using the ion symbol $\left(\mathrm{Na}, \mathrm{K}, \mathrm{Mg}\right.$ and $\left.\mathrm{Ca}, \mathrm{HCO}_{3}\right)$ and expressed in millimoles of charge per liter.

\begin{tabular}{ll}
\hline Parameter & Expression \\
\hline Kelley's Ratio [1] & $\mathrm{KR}=\frac{\mathrm{Na}}{(\mathrm{Ca}+\mathrm{Mg})}$ \\
Percent Sodium [2] & $\% \mathrm{Na}=\frac{\mathrm{Na} \times 100}{(\mathrm{Na}+\mathrm{K}+\mathrm{Ca}+\mathrm{Mg})}$ \\
Soluble Sodium Percent (Found) [3] & $\mathrm{SSP}_{f}=\frac{\mathrm{Na} \times 100}{(\mathrm{Na}+\mathrm{Ca}+\mathrm{Mg})}$ \\
Residual Sodium Carbonate Eaton [3] & $\mathrm{RSC}=\left(\mathrm{HCO} \mathrm{CO}_{3}\right)-(\mathrm{Ca}+\mathrm{Mg})$ \\
Sodium Adsorption Ratio [4] & $\mathrm{SAR}=\frac{\mathrm{Na}}{\sqrt{(\mathrm{Ca}+\mathrm{Mg}) / 2}}$ \\
Cation Ratio of soil Structural Stability [5] & $\mathrm{CROSS}=\frac{\mathrm{Na}+(0.56) \cdot \mathrm{K}}{\sqrt{(\mathrm{Ca}+(0.6) \cdot \mathrm{Mg}) / 2}}$ \\
$\qquad \mathrm{SSP}_{p}=\left\{\begin{array}{lll}\frac{\mathrm{Na} \times 100}{(\mathrm{Na}-\mathrm{RSC})}, & \text { if } \quad(\mathrm{Ca}+\mathrm{Mg})>\left(\mathrm{HCO}_{3}+\mathrm{CO}_{3}\right) \\
100 \%, & \text { otherwise }\end{array}\right.$
\end{tabular}

Eaton [3] recognized source water alkalinity somehow determined whether salinization produced non-alkaline saline or alkali soils. Unfortunately, Eaton's RSC (Table 1) assumes calcite precipitation removes $\mathrm{Mg}$ and Ca simultaneously and proportionately. This assumption is unfounded as explained by [6], meaning $\mathrm{SSP}_{p}$ cannot reach $100 \%$ as implied by expression (1).

Kelley's Ratio KR, Wilcox's \%Na, Eaton's $\mathrm{SSP}_{f}$, SAR and CROSS all stress the relative importance of dissolved sodium but only SAR is empirically linked [4] to the exchangeable sodium ratio ESR (2), making it most favored predictor of sodium hazard.

$$
\mathrm{ESR}=0.01475 \cdot \mathrm{SAR}-0.0126
$$

Recently, $[5,7]$ developed a new water quality parameter. The cation ratio of soil structural stability CROSS (Table 1) expands and modifies SAR to account for the dispersive properties of $\mathrm{K}^{+}$and to more precisely account for the flocculating capacity of $\mathrm{Mg}^{2+}$ relative to $\mathrm{Ca}^{2+}$. The U.S. Salinity Laboratory [4] originally introduced the potassium adsorption ratio PAR to account for the dispersive properties of $\mathrm{K}^{+}$but the PAR was largely ignored as a water quality parameter until the introduction of CROSS [5, 8].

Rengasamy and Marchuk [5] found a close correlation between the Exchangeable Cation Ratio ECR\% (3) and CROSS using 18 soils from Australia. The U.S. Salinity Laboratory regression (2) was based on 59 soils from 9 Western U.S. states [4]. 


$$
\mathrm{ECR} \%=\frac{n_{\mathrm{Na}} / m+n_{\mathrm{K}} / m}{2 \cdot\left(n_{\mathrm{Ca}} / m+n_{\mathrm{Mg}} / m\right)} \cdot 100
$$

Regardless of the relative merits of SAR or CROSS, the approach described in this paper relates specifically to the effect of soil water loss on calcite solubility and applies equally to SAR and CROSS evolution during salinization.

\subsection{Empirical Lysimeter Results}

Rhoades and co-workers [9-11] published the results of a series of lysimeter studies in which the Pachappa soil [12] was irrigated with eight synthetic waters, each representative of a specific river located in the western U.S. (Table 2).

These studies remain relevant today despite being published nearly 50 years ago. First, the lysimeter data is high quality and is confirmed independently, as we will see below, by river data collected by the U.S. Geological Survey over intervals ranging from 3 to 6 decades. Such independent confirmation of the effects of salinization on major ion composition is found no where else in the scientific literature. Second, the chemical composition of the eight source waters spans a range from low to high sodium risk. Third, the leaching-fraction treatments result in sufficient water loss to discern the salinization effect on drainage water composition, which is confirmed independently by the U.S. Geological Survey data mentioned above. Fourth, the data also dramatically demonstrate how salinization reveals the latent sodium risk of these various source waters.

The drainage water composition from the lysimeter studies clearly demonstrates the (EC, SAR) path for each source water is distinct (Figure 1). The river water results plotted in Figure 1 are substantially similar to the lysimeter drainage wzter data plotted in Figure 4 of [11] whose numerical values are, unfortunately, unavailable.

\section{Methods and Materials}

We evaluated seven out of eight irrigation waters from lysimeter studies previously published in the scientific literature $[9,10]$. Data from the Feather River was not included because water loss resulted in electrical conductivity values no greater than $0.3 d S \cdot m^{-1}$.

Table 2 lists the partial composition of synthetic river waters used by $[9$, 10]) in their lysimeter studies. The synthetic irrigation waters do not capture the complete composition range of any of the rivers. The rationale for selecting these particular rivers, the specific sampling locations and other useful details about these waters were not revealed by the authors.

Briefly, Rhoades and his coworkers used 48 lysimeters with $51 \mathrm{~cm}$ in diameter and $137 \mathrm{~cm}$ deep, irrigated to leaching fractions (LF) of $0.1,0.2$ and 0.3 with replications. Lysimeters were filled with Pachappa soil (coarse-loamy, mixed, active, thermic Mollic Haploxeralfs). The Pachappa soil in half of the lysimeters 


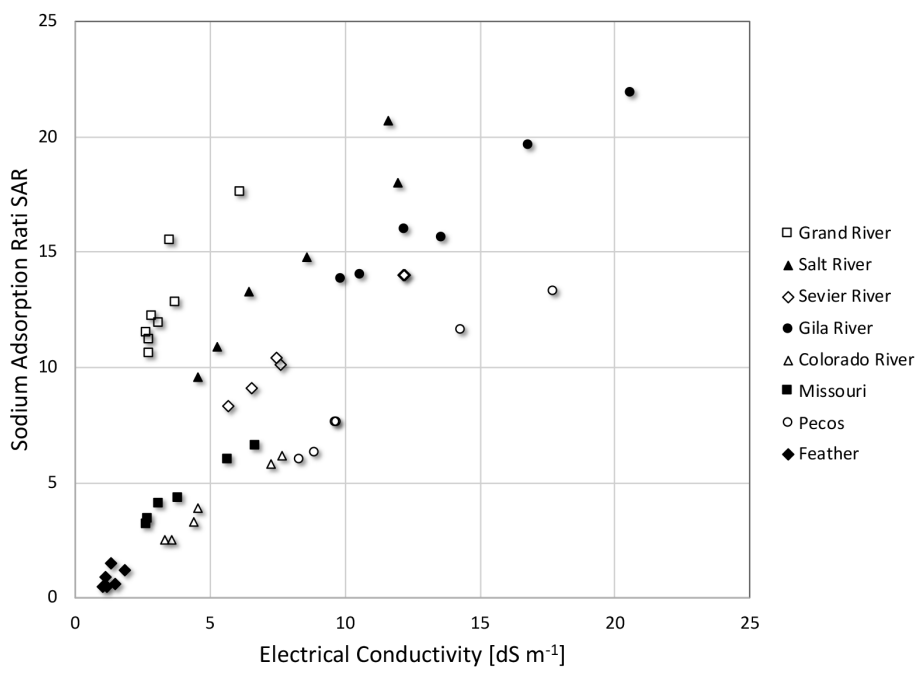

Figure 1: Drainage water results from [9] and [10] for calcareous and non-calcareous lysimeters. This figure did not appear in [9] or [10] and appears here for the first time.

Table 2: Select major ion concentrations (units: $\mathrm{mmol}_{c} \cdot d \mathrm{~m}^{-3}$ ) and solution parameters (sodium adsorption ratio SAR and alkalinity-to-calcium moles-of-charge ratio) for seven synthetic river waters used in lysimeter studies by $[9,10])$. Results for the Feather River are not included because the salinity and SAR ranges are very narrow compared to the salinity and SAR ranges for the other rivers.

\begin{tabular}{lccccccc}
\hline River & $\mathrm{Ca}$ & $\mathrm{Mg}$ & $\mathrm{Na}$ & $\mathrm{HCO}_{3}$ & $\mathrm{EC}_{\mathrm{iw}}$ & $\mathrm{SAR}_{\mathrm{iw}}$ & $\mathrm{Alk}_{\mathrm{iw}} / \mathrm{Ca}_{\text {iw }}$ \\
\hline Grand & 2.00 & 0.79 & 7.08 & 6.29 & 0.94 & 5.99 & 3.15 \\
Sevier & 3.71 & 6.05 & 10.62 & 5.21 & 2.03 & 4.81 & 1.40 \\
Salt & 3.15 & 1.35 & 9.62 & 3.21 & 1.56 & 6.41 & 1.02 \\
\hline Gila & 7.22 & 5.88 & 18.55 & 3.17 & 3.14 & 7.25 & 0.18 \\
Pecos & 16.98 & 9.07 & 11.38 & 3.11 & 3.26 & 3.15 & 0.44 \\
Colorado & 6.95 & 3.63 & 3.35 & 3.73 & 1.27 & 1.46 & 0.54 \\
Missouri & 4.06 & 1.92 & 3.02 & 3.24 & 0.91 & 1.75 & 0.80 \\
\hline
\end{tabular}


were mixed with $1 \%$ of $\mathrm{CaCO}_{3}$. All lysimeters were planted with alfalfa and irrigated with the eight synthetic waters listed in Table 2. Drainage water samples from lysimeters were collected and analyzed at $30 \mathrm{~cm}$ intervals during 21 days. Results from the lysimeter studies appear in three papers [9-11]. Rhoades et al. $[9,10]$ collected and analyzed soil drainage water at field capacity in calcareous and non-calcareous soil; [11] report saturated paste extracts from the calcareous lysimeter.

\subsection{Sodium Adsorption Ratio Boundary Expressions}

When the equivalent concentration of alkalinity is larger than calcium in the initial water, increasing salinity drives calcite precipitation and alkalinity enrichment (Figure 2 and Figure 3); the dissolved calcium remaining becomes small relative to soluble magnesium. At the limit where the equilibrium calcium concentration is very small relative to magnesium, the SAR of drainage water is determined by the soluble sodium and magnesium in the source water.

The reader is referred to Appendix A through Appendix C for a detailed review of salinity theory and previously developed expressions designed to project changes in SAR during salinization and mass-transfer water chemistry simulations implementing the Hardie and Eugster [13] protocol.

A modified SAR index, which we call the limiting sodium adsorption ratio or LSAR (4) is based on the initial $\mathrm{Na}, \mathrm{Mg}$, and the salinization concentration factor (5). The LSAR (4) defines the upper SAR limit; it represents the worst-case scenario. Briefly, if $\mathrm{Alk}_{\mathrm{iw}} / \mathrm{Ca}_{\mathrm{iw}}>1$, virtually all soluble calcium can be removed through calcite precipitation. Water with excess alkalinity $\mathrm{Alk}_{\mathrm{iw}} / \mathrm{Ca}_{\mathrm{iw}}>1$ and a high sodium-to-magnesium $\mathrm{Na}_{\mathrm{iw}} / \mathrm{Mg}_{\text {iw }}$ ratio pose the greatest sodium risk, tending follow of the steepest (EC, SAR) paths in Figure 1.

$$
\begin{gathered}
\operatorname{LSAR}\left(F_{c}\right)=\sqrt{F_{c}} \cdot \frac{\mathrm{Na}_{\mathrm{iw}}}{\sqrt{\mathrm{Mg}_{\mathrm{iw}} / 2}} \\
F_{c}=E C_{d w} / E C_{i w}=1 / L F
\end{gathered}
$$

When the equivalent concentration of alkalinity is less than calcium in the initial water $\left(\mathrm{Alk}_{\mathrm{iw}} / \mathrm{Ca}_{\mathrm{iw}}<1\right)$ soluble calcium follows much the same path of sodium and magnesium as water is lost by evaporation. The drainage water SAR tends to follow, in this case, the evaporation-adjusted sodium adsorption ratio or ESAR (6). The ESAR projects the lower boundary based on initial dissolved sodium, magnesium and calcium in the water; it represents the lowest possible SAR limit under evaporation and can be considered the best-case scenario.

$$
\operatorname{ESAR}\left(F_{c}\right)=\sqrt{F_{c}} \cdot \frac{\mathrm{Na}_{\mathrm{iw}}}{\sqrt{\left(\mathrm{Ca}_{\mathrm{iw}}+\mathrm{Mg}_{\mathrm{iw}}\right) / 2}}
$$


According to expressions (4) and (6), we can plot the upper and lower drainage water SAR boundaries based solely on the initial content of $\mathrm{Na}, \mathrm{Mg}$, $\mathrm{Ca}$ and Alk of the irrigation water. Expressions (4) and (6) make no attempt to predict calcium solubility during salinization, unlike Appendix $\mathrm{C}$ expressions (C.1) and (C.2). Hence, expressions (4) and (6) do not require any assumption regarding $p_{\mathrm{CO}_{2}}$.

\section{Results}

The results in plotted in Figure 2 and Figure 3 and listed in and Table 3 apply the analysis of [13] which, needless to say, was not applied by $[9,10]$. The results in plotted in Figure 4 use data from the U.S. Geological Survey for the rivers listed in Table 2. Results in plotted in the remaining figures use data published by $[9,10]$ but appear here in graphic form for the first time.

Figure 2 clearly demonstrates the $1 \%$ calcite treatment to half of the 48 lysimeters had no effect on the relative moles-of-charge ratio $\mathrm{Alk}_{\mathrm{dw}} / \mathrm{Ca}_{\mathrm{dw}}>1$ of the drainage water. This come as no surprise because calcite precipitation is the first decisive salinization event regardless of the subsequent salinization pathway.

The results appearing in Figure 2 have additional significance; they confirm both the quality and veracity of the lysimeter experiments and drainage water analyses published by $[9,10]$.

Figure 3 results clearly distinguishes the two most alkaline source waters (Feather River and Grand River) from the remaining low alkaline source waters. It is quite evident dissolved calcium concentrations are nearly 10 -fold lower in the Grand and Feather rivers relative to the Gila River, a distinguishing characteristic of surface and ground waters that contributes to sodium risk. All drainage water data appearing in Figure 2 and Figure 3 are clearly calcite saturated.

Calcium concentrations in drainage water from the lysimeters irrigated by Grand River water (Figure 3) decline as the $\mathrm{Alk}_{\mathrm{dw}} / \mathrm{Ca}_{\mathrm{dw}}$ moles-of-charge ratio increases during salinization, an indication that drainage water SAR values trend to higher values as calcite continues to precipitate.

Calcium concentrations in drainage water from the lysimeters irrigated by Pecos and Gila river waters (Figure 3) increase as the $\mathrm{Alk}_{\mathrm{dw}} / \mathrm{Ca} \mathrm{dw}_{\mathrm{dw}}$ moles-ofcharge ratio decreases during salinization, an indication that drainage water SAR values trend to lower values as calcite continues to precipitate.

The different (EC, SAR) paths for six source river waters are shown in Figure 4. Each source river water has a similar salinization path as its corresponding drainage water collected from the lysimeter experiments (Figure 1). Not only do the results in Figure 4 confirm the quality of the lysimeter data in Figure 1, these data suggests the evaporation-driven (EC, SAR) path is determined by the distinctive major-ion chemistry of each source water, not by the chemical weathering of the Pachappa soil during the residence time of water in the lysimeters. 


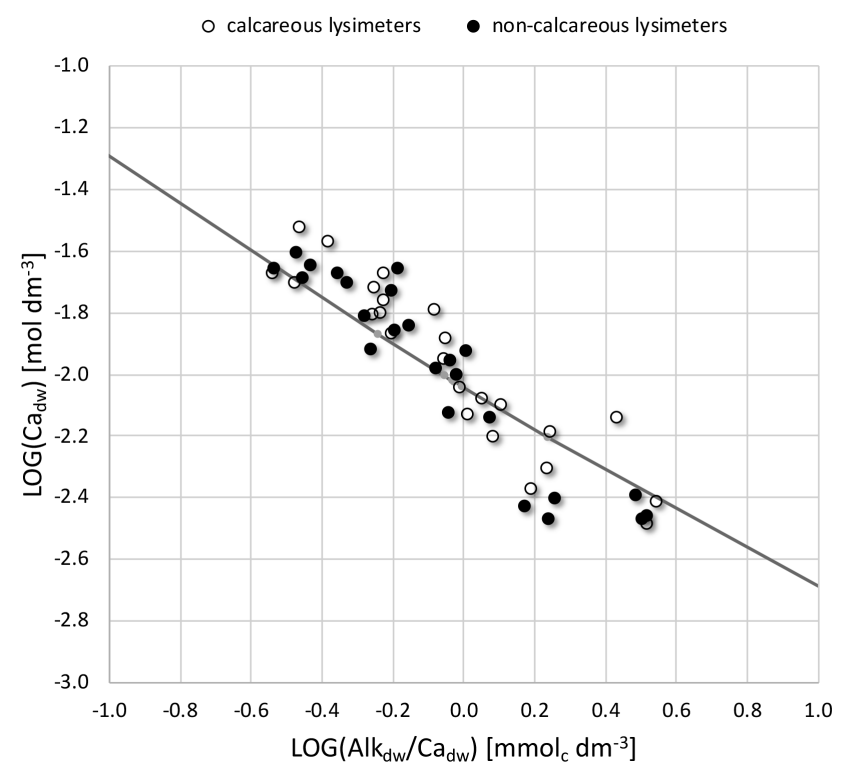

Figure 2: Drainage water results from $[9,10]$ showing the variation in the dissolved $\mathrm{Ca}$ in drainage water as a function of the moles-of-charge ratio $\left(\mathrm{Alk}_{\mathrm{dw}} / \mathrm{Ca}_{\mathrm{dw}}\right)$. Data from calcareous plotted as open circle and from non-calcareous plotted as filled circle. The solid line represents calcite solubility at $p \mathrm{CO}_{2}=1 \mathrm{~atm}$. 


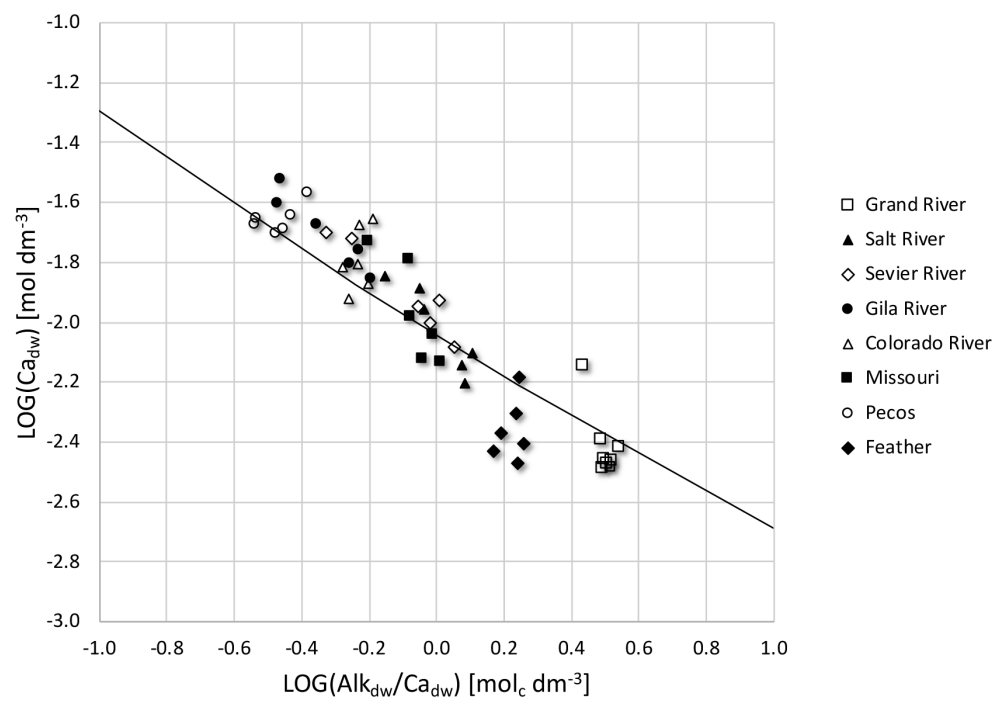

Figure 3: Drainage water results from $[9,10]$ showing the variation in the dissolved $\mathrm{Ca}$ in drainage water as a function of the moles-of-charge ratio $\left(\mathrm{Alk}_{\mathrm{dw}} / \mathrm{Ca} \mathrm{dw}_{\mathrm{w}}\right)$. The solid line represents calcite solubility at $p \mathrm{CO}_{2}=1 \mathrm{~atm}$.

River discharge consists of a small volume of base flow derived from the groundwater with a long residence time and a much higher volume of interflow derived from water entering the soil, percolating through vadose zone and recharging the water table. Interflow discharge has a residence time measured in months rather than decades. River water variation over several annual cycles (Figure 4) has much in common with the lysimeter drainage water variations found in Figure 1, driven by evaporative soil water loss. In short, the distinct drainage water (EC, SAR) path seen in Figure 1 are simply a continuation of the distinct (EC, SAR) path apparent in the interflow discharged into each river (Figure 4).

As water loss by evaporation increased salinity, each drainage water follows a distinct (EC, SAR) path. The eight water sources differ in their latent sodium risk, which only became apparent at moderate to high salinity as calcite precipitation begins to significantly alter drainage water (or interflow) composition. If the equivalent concentration of calcium is larger than alkalinity, the water should remain near ESAR boundaries. If the equivalent concentration of calcium is smaller than alkalinity, the drainage water SAR should approach the upper LSAR boundary.

Figure 5 and Figure 6 plot data from lysimeter studies of $[9,11]$. The water compositions listed in Table 2 were used to draw the boundaries using expressions (4) and (6). The Grand River at Wakpala (Figure 5) and the Sevier River at Lynndyl (Figure 6) represented source waters that contained more 


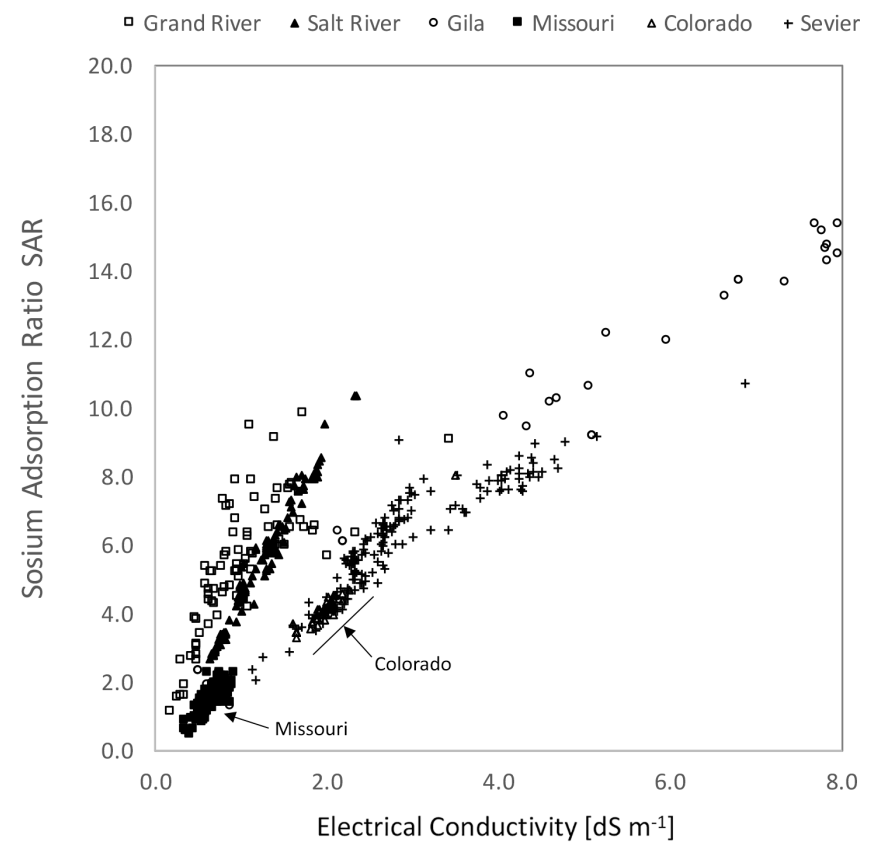

Figure 4: Electrical conductivity EC and sodium adsorption ratio SAR of six rivers from the western U.S. These river data are from U.S. Geological Survey. Open square symbols are the Grand River at Wakpala, South Dakota; filled triangle symbols are Salt River below Stewart Mountain Dam, New Mexico; open circle symbols are Gila River below Gillespie Dam, New Mexico; filled square symbols are Missouri River at Nebraska City, Nebraska; open triangle symbols are Colorado River above Morelos Dam, Arizona; crossing symbols are Sevier River at Lynndyl, Utah. 


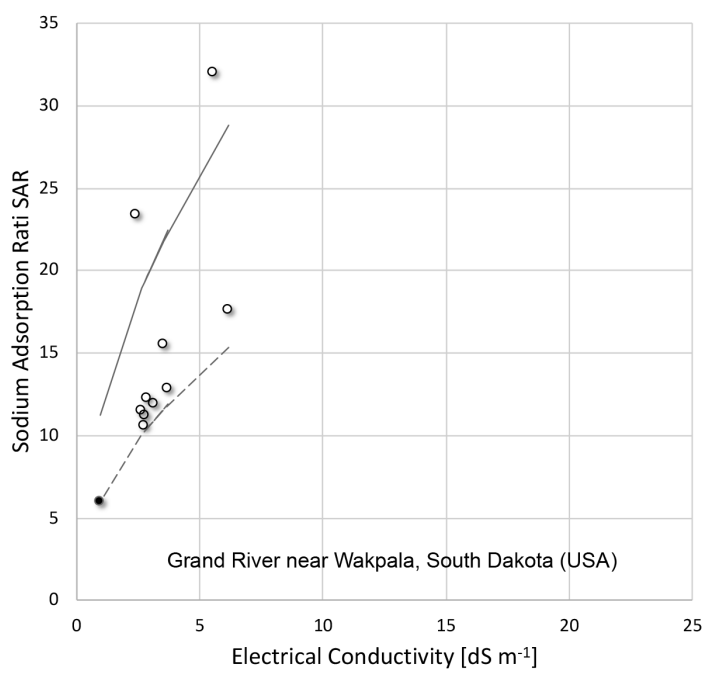

Figure 5: Drainage water composition (open circles) from lysimeters irrigated with synthetic water (filled circle) representative of the Grand River near Wakpala, South Dakota (Source: $[9,10]$ ). The LSAR (solid) and ESAR (dashed) boundaries were projected from the source composition (filled circle).

alkalinity than calcium. As salinity increased by evaporation, alkalinity removes virtually all the original dissolved calcium through calcite precipitation. The water analyzed in the lysimeter study had the tendency to migrate to the upper limit, LSAR boundary.

Figure 7 plots lysimeter drainage water (EC, SAR) data for the Salt River. As the result of water loss by evaporation, drainage water chemistry remains close to the lower ESAR boundary.

Figure 8 and Figure 9 show the lysimeter drainage water results for the Gila River and the Missouri River. The two waters are characterized by $\mathrm{Alk}_{\mathrm{dw}} / \mathrm{Ca}_{\mathrm{dw}}<$ 1. The (EC, SAR) paths of the lysimeter drainage water remained between the upper LSAR and lower ESAR boundaries. Furthermore, the salinization path for river water and soil drainage water for these two rivers are remarkably similar.

The soil drainage data of the Colorado River near Mexican Border is shown in Figure 10. The Colorado River at this location is a low alkalinity river $\left(\mathrm{Alk}_{\mathrm{dw}} / \mathrm{Ca}_{\mathrm{dw}}<1\right)$. The drainage water compositions from the lysimeter studies are once again bounded by the LSAR and ESAR.

Table 3 provides a direct comparison of results from reaction-path simulations of the seven waters after water loss by evaporation increases EC to $4 d S \cdot m^{-1}$ with predictions made using boundary expressions introduced above.

Reaction-path mass-transfer simulations based on the initial major ion composition concentrated by evaporation to a salinity of $4 d S \cdot m^{-1}\left(\mathrm{SAR}_{r p}\right.$ Table 3 , 


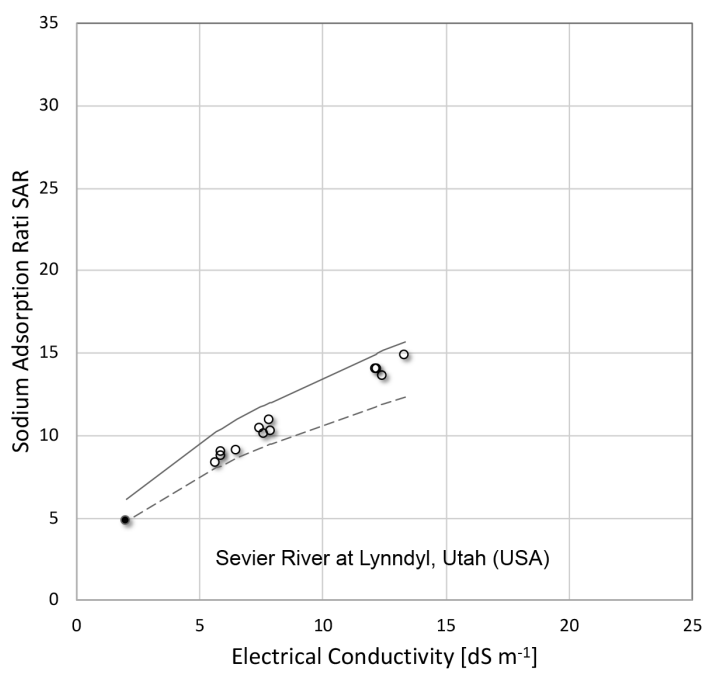

Figure 6: Drainage water composition (open circles) from lysimeters irrigated with synthetic water (filled circle) representative of the Sevier River at Lynndyl, Utah (Source: $[9,10])$. The LSAR (solid) and ESAR (dashed) boundaries were projected from the source composition (filled circle).

column 4). See Appendix A (Mass-Transfer Water Chemistry Simulations) for complete details. Mass-transfer simulation yields the most complete estimate of SAR because it accounts for all solution species. The $\mathrm{CO}_{2}(\mathrm{~g})$ partial pressure was set at $p_{\mathrm{CO}_{2}}=1 \mathrm{~atm}$, consistent with the results in Figure 2 and Figure 3.

The third-order polynomial estimates (Table 3, column 5) rely solely on the initial $\mathrm{Ca}$ and Alk and the concentration factor needed to reach $4 \mathrm{dS} \cdot \mathrm{m}^{-1}$ to estimate $\mathrm{Ca}_{\mathrm{eq}}$. The Newton-Raphson estimates of the third-order polynomial (expression (cf. C.4)) closely match those in column 4, as expected. The level of difficulty solving a third-order polynomial is certainly less than a complete reaction-path mass-transfer simulation but convergence of the Newton-Raphson approximation required as many as 9 iterations.

\section{Discussion}

With the exception of a few data points (cf. Figure 5 and Figure 11) drainage water compositions are bounded by LSAR and ESAR boundaries drawn using expressions (4) and (6). The results presented in Figure 5 through Figure 11 demonstrated the usefulness of a simple new method for predicting the relationship of EC and SAR of irrigation drainage waters by drawing boundaries for each water source.

The results in Figure 5 through Figure 11 demonstrate salinization is dy- 


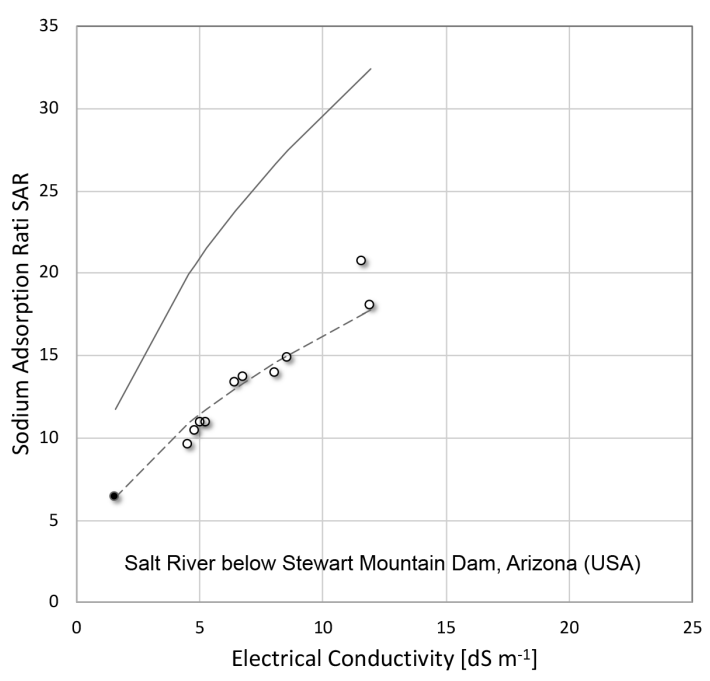

Figure 7: Drainage water composition (open circles) from lysimeters irrigated with synthetic water (filled circle) representative of the Salt River below Stewart Mountain Dam, Arizona (Source: $[9,10])$. The LSAR (solid) and ESAR (dashed) boundaries were projected from the source composition (filled circle).

Table 3: Column 2 lists the alkalinity-to-calcium moles-of-charge ratio for each source water and column 3 lists the concentration factor $F_{c}$ needed to concentrate salinity to $4 d S \cdot m^{-1}$. Columns 4-7 list estimates of the sodium adsorption ratio SAR resulting from salinization. The $\mathrm{SAR}_{r p}$ estimates in column 4 are based on reaction-path modeling accounting for calcite precipitation during salinization to $4 d S \cdot \mathrm{m}^{-1}$ (Appendix B). The polynomial estimates in column 5 are the real root of third-order polynomial (C.4) found using the Newton-Raphson method (Appendix C). The values in columns 6 and 7 were computed using (4) and (6), respectively.

\begin{tabular}{lcccccc} 
River & $\mathrm{Alk}_{\text {iw }} / \mathrm{Ca}_{\mathrm{iw}}$ & $F_{c}$ & $\mathrm{SAR}_{r p}$ & 3rd-order polynomial & LSAR & ESAR \\
\hline Grand & & & & & & \\
Sevier & 3.15 & 4.26 & 23.11 & 23.23 & 23.24 & 12.37 \\
Salt & 1.40 & 1.97 & 8.56 & 8.54 & 8.57 & 6.75 \\
Pecos & 1.02 & 2.56 & 15.63 & 16.80 & 18.75 & 10.27 \\
Gila & 0.18 & 1.23 & 3.70 & 3.71 & 5.92 & 3.49 \\
Colorado & 0.44 & 1.27 & 9.10 & 9.25 & 12.21 & 8.18 \\
Missouri & 0.54 & 3.15 & 3.19 & 3.19 & 4.41 & 2.58 \\
\hline
\end{tabular}




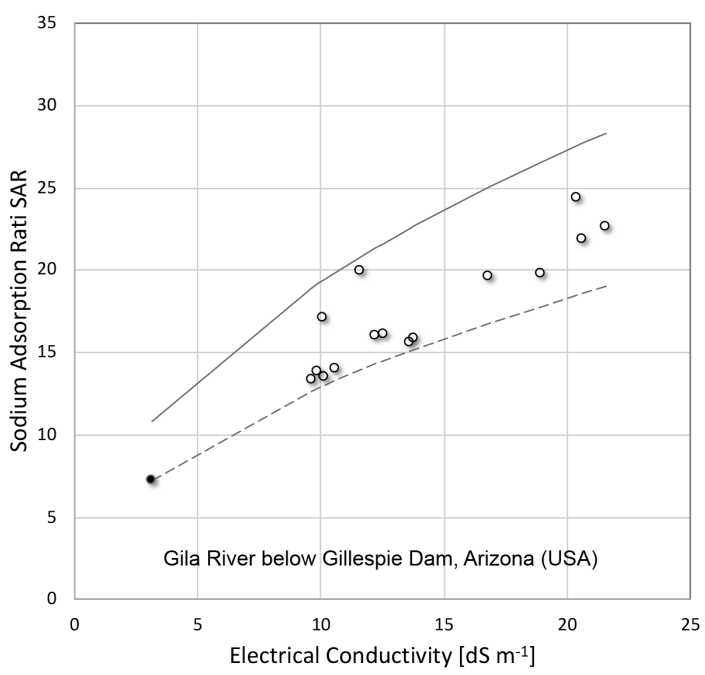

Figure 8: Drainage water composition (open circles) from lysimeters irrigated with synthetic water (filled circle) representative of the Gila River below Gillespie Dam, Arizona (Source: $[9,10]$ ). The LSAR (solid) and ESAR (dashed) boundaries were projected from the source composition (filled circle).

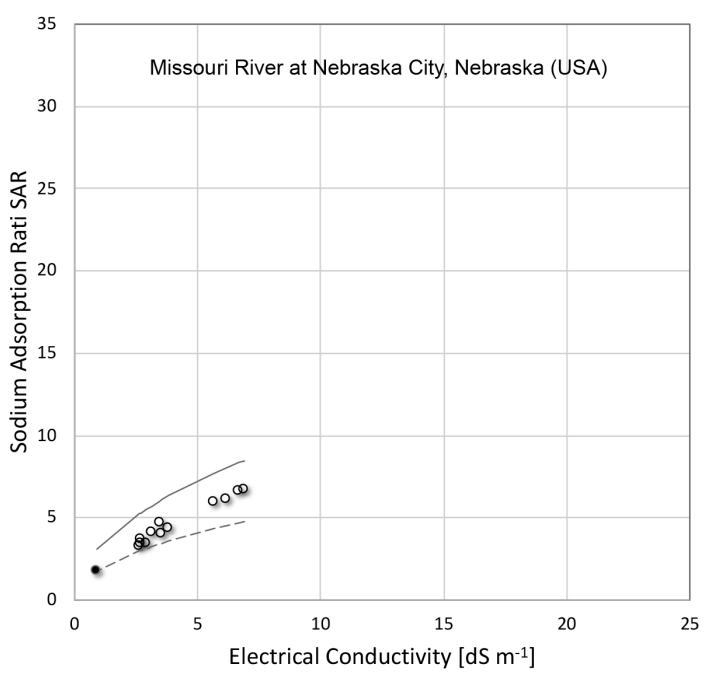

Figure 9: Drainage water composition (open circles) from lysimeters irrigated with synthetic water (filled circle) representative of the Missouri River at Nebraska City, Nebraska (Source: [9, 10]). The LSAR (solid) and ESAR (dashed) boundaries were projected from the source composition (filled circle). 


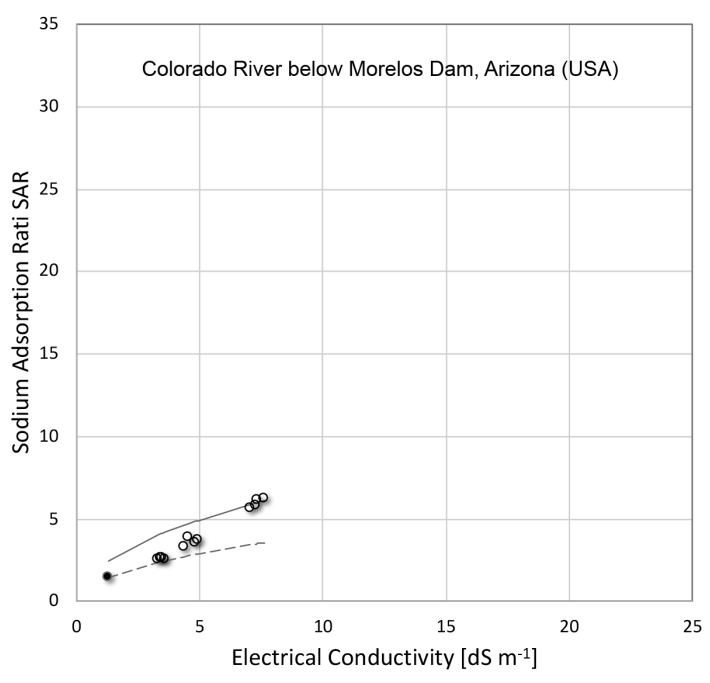

Figure 10: Drainage water composition (open circles) from lysimeters irrigated with synthetic water (filled circle) representative of the Colorado River near Mexican Border below Morelos Dam, Arizona (Source: $[9,10]$ ). The LSAR (solid) and ESAR (dashed) boundaries were projected from the source composition (filled circle). 


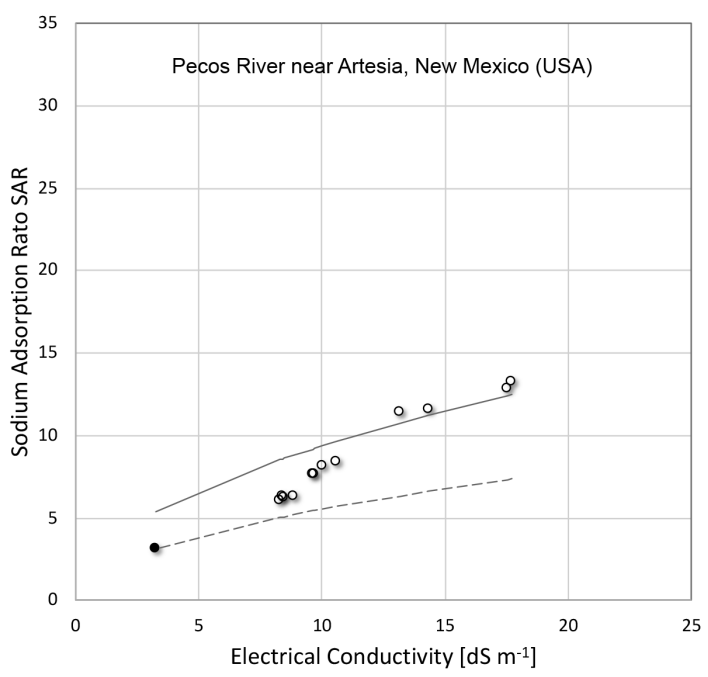

Figure 11: Drainage water composition (open circles) from lysimeters irrigated with synthetic water (filled circle) representative of the Pecos River near Artesia, New Mexico (Source: $[9,10]$ ). The LSAR (solid) and ESAR (dashed) boundaries were projected from the source composition (filled circle).

namic process that results in a range of compositions even when a single sourcewater composition is used. These results also highlight the limitation of using equilibrium water chemistry to simulate the dynamic chemical processes. If we account for seasonal variability of surface water sources (cf. Figure 4) then it becomes clear that a single-point cannot represent the full composition range delivered by a surface water source at a particular site over an annual cycle. The proposed LSAR and ESAR bounds (Table 3, columns 6 and 7) offer a reasonable estimate of the SAR range at a minimum computational effort.

When $\mathrm{Alk}_{\mathrm{iw}} / \mathrm{Ca}_{\mathrm{iw}}>1$ evaporation-driven $\mathrm{SAR}$ values trend toward the LSAR value; drainage water will approach to the upper LSAR boundary. When $\mathrm{Alk}_{\mathrm{iw}} / \mathrm{Ca}_{\mathrm{iw}}<1$, evaporation-driven SAR values remain close to the ESAR limit; drainage water will stay slightly above the lower ESAR boundary.

\subsection{Practical Application}

The practical application of the proposed method for assessing the sodium risk begins with the water analysis: soluble sodium, calcium, magnesium, alkalinity and electrical conductivity. The salinization pathway is determined by the relative concentration of calcium and alkalinity: the "alkalinity-enriched" path salinization develops if $\mathrm{Alk}_{\mathrm{dw}} / \mathrm{Ca}_{\mathrm{dw}}>1$, the "alkalinity-depleted" salinization develops if $\mathrm{Alk}_{\mathrm{dw}} / \mathrm{Ca}_{\mathrm{dw}}<1$.

Based on the salinity pathway, drainage water will either approach the upper 
LSAR boundary or remain close to the lower ESAR boundary. If the water shows no sodium risk after evaporation reaches the salinity tolerance of the crop, then the leaching fraction is determined solely by tolerable salinity. If at the tolerable salinity, the projected drainage water SAR is falls above the tolerable limit, then drainage water SAR rather than crop salinity tolerance should dictate the recommended leaching fraction.

A similar assessment follows if the water quality parameter being projected is the cation ratio of soil structural stability CROSS [5]. A discussion of the implications of calcite precipitation for the evolution of CROSS during soil water loss is beyond the scope of this paper.

\section{Conclusion}

Our results show the lysimeter data from $[9,10]$ are confined by the LSAR and ESAR boundaries calculated using expressions (4) and (6) computed using the source water composition. Furthermore, the lysimeter data for each source water follows the same (EC, SAR) path as the source river (cf. Figure 4) which demonstrating the initial water composition determines the (EC, SAR) path during salinization.

This paper suggests a simple method to rate the sodium hazard of irrigation sources that dispenses with the necessity to: 1) perform complex reactionpathway water chemistry simulations which implement the method developed by [14] or 2) solve the abbreviated solution model embodied in the second-order polynomial of [15] (Appendix C, expression (C.3)) or the third-order polynomial of [16] (Appendix C, expression (C.4)).

The unresolved question of the appropriate $\mathrm{CO}_{2}(\mathrm{~g})$ partial pressure $p_{\mathrm{CO}_{2}}$ generated considerable discussion in [16-18] without any clear guidance for hydrochemists attempting to assess the sodium hazard of irrigation sources.

Hardie and Eugster [13] assumed the appropriate $p_{\mathrm{CO}_{2}}$ for saline lakes is the atmospheric level. Oster and McNeal [15] based $p_{\mathrm{CO}_{2}}$ in their study on the "estimated partial pressure of carbon dioxide in the laboratory atmosphere". Suarez [18] chose $p_{\mathrm{CO}_{2}}=0.13 \mathrm{~atm}$ to model results from the lysimeter study of [10]. Needless to say, the appropriate $p_{\mathrm{CO}_{2}}$ for assessing the sodium hazard based on source-water chemical composition remains an open question.

The carbon dioxide partial pressure $p_{\mathrm{CO}_{2}}$ is not a decisive parameter determining the salinization path emerging from the calcite chemical divide. The salinization path emerging from the calcite chemical divide depends solely on the alkalinity-to-calcium moles-of-charge ratio $\mathrm{Alk}_{\mathrm{iw}} / \mathrm{Ca}_{\mathrm{iw}}$ of the water source.

Although the LSAR-ESAR method introduced here only predicts a reasonable SAR range for each source waters instead of a single SAR value, it offers a simple and practical assessment of the sodium hazard for irrigation water sources. In fact, setting chemically reasonable range is more realistic than a specific-point prediction given seasonal variability in surface water composition and the uncertain calcite precipitation rate under field conditions. 


\section{Acknowledgements}

This work was supported by the United States Golf Association and Agricultural Experiment Station (Hatch project WIS01848), University of WisconsinMadison

\section{Appendices}

\section{Appendix A: Hardie-Eugster Salinization Theory}

Hardie and Eugster [13] applied the reaction-path principles (cf. Appendix B) developed by [19] to the specific case of evaporative concentration. They defined four salinization pathways that depended on the initial composition of the water before evaporative concentration begins. Associated with these four salinization pathways are three chemical divides defined by calcite, gypsum and sepoilite stoichimetry. Only the calcite chemical divide pertains to the the sodium hazard of non-saline irrigation water because gypsum saturation occurs in the $3-4 d S \cdot m^{-1}$ range typically considered saline.

Hardie and Eugster [13] concluded two restrictions must apply throughout calcite precipitation: 1) the ions $\mathrm{Ca}^{2+}$ and $\mathrm{CO}_{3}^{2-}$ are removed from solution in equal molar proportions, and 2) the ion activity product of these two ions must remain constant.

"Now, because the initial molar proportions in general will not be equal, the first restriction implies that the $\mathrm{Ca}^{2+}$ to $\mathrm{CO}_{3}^{2-}$ proportions in the solution must change as calcite precipitates. The second restriction allows only antipathetic changes in $\mathrm{Ca}^{2+}$ and $\mathrm{CO}_{3}^{2-}$ concentrations, that is, if $\mathrm{Ca}$ increases then $\mathrm{CO}_{3}^{2-}$ must decrease, and vice versa. Clearly, then, early calcite precipitation is a critical evolutionary step; it will immediately determine whether an evaporating water will become carbonate-rich or carbonate-poor."

Emerging from calcite chemical divide are two salinization pathways: 1) an alkaline or carbonate-enriched pathway which pertains if alkalinity-to-calcium moles-of-charge ratio is greater than one and 2) a neutral or carbonate-depleated pathway which pertains if the alkalinity-to-calcium moles-of-charge ratio is less than one. The carbonate-enriched pathway is the same salinization pathway identified by [3] leading to alkali soils while the carbonate-depleted pathway leads to calcium saline soils.

Hardie and Eugster [13] proposed a residual alkalinity parameter $\Delta$ (A.1) which predicts the salinization path emerging from the calcite-precipitation chemical divide.

$$
\Delta=\left(\mathrm{Ca}_{\mathrm{iw}}-\mathrm{Alk}_{\mathrm{iw}}\right)
$$




$$
\operatorname{Alk}\left[m o l_{c} \cdot d m^{-3}\right]=\left(c_{\mathrm{HCO}_{3}^{-}}-2 \cdot c_{\mathrm{CO}_{3}^{2-}}\right)
$$

After mineralized water enters the soil, evaporative water loss increases dissolved calcium and alkalinity in direct proportion to the concentration factor $F_{c}(5)$ which is expressed as the drainage-water electrical conductivity $\mathrm{EC}_{d w}$ divided by irrigation-water electrical conductivity $\mathrm{EC}_{i w}$ or the inverse of the leaching fraction $L F$.

Simulations of the mass-transfer process involved in calcite precipitation following the protocol given by [13], reveal the common-ion effect on solution composition. Briefly, if the equivalent ratio $\mathrm{Alk}_{\mathrm{iw}} / \mathrm{Ca}_{\mathrm{iw}}>1$ then the commonion effect coupled to evaporation will drive soluble calcium downward. If the equivalent ratio $\mathrm{Alk}_{\mathrm{iw}} / \mathrm{Ca}_{\mathrm{iw}}<1$, the common-ion effect coupled to evaporation will drive alkalinity downward. The common-ion effect suggests solution SAR is confined between two composition limits determined by the initial concentration of $\mathrm{Na}, \mathrm{Mg}, \mathrm{Ca}$ and alkalinity Alk in the source water.

It is perhaps predictable the soil science community ignored [13] because explicit topic of their paper was the evolution of saline lakes not soil salinity. Regardless, there are a few instances where soil chemists developed chemical models (cf. Appendix C) that align with the principles laid out by [19].

\section{Appendix B: Mass-Transfer Water Chemistry Sim- ulations}

The following applies the reaction-path method developed by [19] to the specific case of $\mathrm{CaCO}_{3}$ mass transfer driven by solution evaporation as it appears in [13].

Each mass-transfer simulation was all carried out at a fixed salinity of $4 d S$. $m^{-1}$ which required a different concentration factor $F_{\mathrm{c}}$ for each water source as determined by expression (B.1). For the initial step the calcite ion activity product is computed using the source water composition times the concentration factor $F_{\mathrm{c}}$ yielding $E C=4 d S \cdot \mathrm{m}^{-1}$. If the solution is calcite over-saturated mass transfer moves $\mathrm{Ca}$ and Alk from solution to calcite so as to preserve the stoichiometry of the calcite product.

For example, if $\mathrm{Alk}_{\mathrm{iw}} / \mathrm{Ca}_{\mathrm{iw}}>1$ for the source water; mass transfer removes calcium equivalents proportionate with the advance of the reaction $\xi$. Expression (B.1) gives the dissolved calcium $\mathrm{Ca}(\xi)$ after an arbitrary mass transfer $\xi$ where the initial state is the source water dissolved calcium $\mathrm{Ca}_{\mathrm{iw}}$ scaled to $E C=4 d S \cdot m^{-1}$. Alkalinity, however, is not reduced proportionate with advance $\xi$ of the mass transfer reaction but, to maintain calcite stoichiometry, it is reduced by an amount equivalent to the calcium removed (B.2).

That is, if $\mathrm{Alk}_{\mathrm{iw}} / \mathrm{Ca}_{\mathrm{iw}}>1$ then (B.1) and (B.2) determine mass transfer $\mathrm{Ca}(\xi)$ and $\operatorname{Alk}(\xi)$. 


$$
\begin{gathered}
\mathrm{Ca}(\xi)=(1-\xi) \cdot\left(4 / F_{c}\right) \cdot \mathrm{Ca}_{\mathrm{iw}} \\
\operatorname{Alk}(\xi)=\left(4 / F_{c}\right) \cdot \mathrm{Alk}_{\mathrm{iw}}-\mathrm{Ca}(\xi)
\end{gathered}
$$

On the other hand: if $\mathrm{Alk}_{\mathrm{iw}} / \mathrm{Ca}_{\mathrm{iw}}<1$ then (4) and (6) determine mass transfer $\mathrm{Ca}(\xi)$ and $\operatorname{Alk}(\xi)$.

$$
\begin{aligned}
& \operatorname{Alk}(\xi)=(1-\xi) \cdot\left(4 / F_{c}\right) \cdot \operatorname{Alk}_{\mathrm{iw}} \\
& \mathrm{Ca}(\xi)=\left(4 / F_{c}\right) \cdot \mathrm{Ca}_{\mathrm{iw}}-\operatorname{Alk}(\xi)
\end{aligned}
$$

\section{Appendix C: Predicting SAR Evolution During Salin- ization}

Attempts to adjust SAR to account for the impact of calcite precipitation have flaws that limit the accuracy of their sodium risk predictions. Bower et al. $[20]$ proposed a SAR adjustment based on the leaching fraction and the Langelier [21] calcite-saturation $\mathrm{pH}$ parameter. The Bower adjusted SAR is still routinely quoted by water testing laboratories but after a brief endorsement [22] in the influential Water Quality for Agriculture this support was withdrawn a decade later [23] to be replaced by endorsement of an alternative method by Suarez [18].

Suarez adjusted the sodium adsorption ratio (C.1) by accounting for water loss leading to a higher drainage water salinity than applied water salinity $\left(E C_{d w}>E C_{i w}\right)$ and the control of dissolved calcium by calcite solubility during water loss $\mathrm{Ca}_{\mathrm{eq}}$ (C.2).

$$
\begin{gathered}
\operatorname{adj}\left(\mathrm{R}_{\mathrm{Na}^{+}}\right)=\sqrt{\frac{E C_{d w}}{E C_{i w}}} \cdot \frac{\mathrm{Na}+}{\sqrt{\left(\mathrm{Ca}_{\mathrm{eq}}+\mathrm{Mg}\right) / 2}} \\
\mathrm{Ca}_{\mathrm{eq}}=\left(\frac{K_{\mathrm{a} 1}^{\ominus} \cdot K_{\mathrm{s} 0}^{\ominus} \cdot H_{\mathrm{CO}_{2}}^{\mathrm{cp}} \cdot p_{\mathrm{CO}_{2}}}{K_{\mathrm{a} 2}^{\ominus} \cdot \gamma_{1 \pm} \cdot \gamma_{2 \pm} \cdot\left(\mathrm{HCO}_{3} / \mathrm{Ca}\right)^{2}}\right)^{1 / 3}
\end{gathered}
$$

Four equilibrium constants appear in (C.2) representing the Henry Law aqueous solubility of $\mathrm{CO}_{2}$, the hydrolysis of $\mathrm{CO}_{2}(\mathrm{aq})$ and $\mathrm{HCO}_{3}^{-}(\mathrm{aq})$, and the solubility of calcite: $H_{\mathrm{CO}_{2}}^{\mathrm{cp}}, K_{\mathrm{a} 1}^{\ominus}, K_{\mathrm{a} 2}^{\ominus}, K_{\mathrm{s} 0}^{\ominus}$, respectively. The activity coefficients for monovalent $\mathrm{HCO}_{3}^{-}(\mathrm{aq})$ and divalent $\mathrm{Ca}^{2+}$ (aq) appear in the denominator. 
The mole ratio $\left(\mathrm{HCO}_{3} / \mathrm{Ca}\right)$ in the denominator of $(\mathrm{C} .2)$ is the ratio for the source water (before salinization by water loss). The method used by [18] constrains $\left(\mathrm{HCO}_{3} / \mathrm{Ca}\right)$ so that at every point in the water-loss process the ratio remains fixed. Hardie and Eugster [13] recognized that preserving calcite stoichiometry during the precipitation process means $\mathrm{HCO}_{3}$ and Ca removal cannot be constrained by a fixed ratio. This invalidates expression (C.2).

Oster and McNeal [15] developed a second-order polynomial (C.3) to predict the effect of mass-transfer through calcite precipitation and, hence, changes in dissolved calcium during water loss. The development of expression (C.3) forced Oster and McNeal (1971) to make certain assumptions about $\mathrm{CO}_{2}(\mathrm{aq})$ levels in the soil to quantify the carbonate concentration. Oster and McNeal [15], though fundamentally correct, fail to mention the importance of the alkalinityto-dissolved calcium ratio on this mass-transfer process and, hence, its control of salinization pathways.

$$
\left(c_{\mathrm{Ca}^{2+}}-x\right) \cdot\left(c_{\mathrm{CO}_{3}^{2-}}-x\right)=\frac{10^{-8.48}}{\gamma_{2+} \cdot \gamma_{2-}}
$$

Šimůnek and Suarez [16] later derived a third-order polynomial (C.4) that eliminated the $\mathrm{CO}_{3}^{2-}$ term, replacing it with two other terms: the dissolved $\mathrm{HCO}_{3}^{-}$concentration and the $\mathrm{CO}_{2}(\mathrm{~g})$ partial pressure $p_{\mathrm{CO}_{2}}$. The third-order polynomial (C.4) is currently used by UNSATCHEM to predict SAR evolution during salinization [24].

$$
\left(c_{\mathrm{Ca}^{2+}}-x\right) \cdot\left(c_{\mathrm{HCO}_{3}^{-}}-2 x\right)^{2}=\frac{10^{-3.05} \cdot p_{\mathrm{CO}_{2}}}{\gamma_{2+} \cdot \gamma_{1-}}
$$

Finding the solution to the third-order polynomial (C.4) is somewhat bothersome. In general, third-order polynomials have one real and two complex roots which makes an algebraic solution anything but routine, though it is possible to program a spreadsheet to find all three roots. A simpler route to the real root relies on the Newton-Raphson method which requires several iterations to converge.

Unlike Hardie and Eugster [13], neither Oster and McNeal [15] or Šimůnek and Suarez [16] recognized the importance of the initial $\mathrm{HCO}_{3}^{-}$-to- $\mathrm{Ca}^{2+}$ mole ratio for the calcite chemical divide; specifically whether water loss leads to carbonate-enriched salinization or carbonate-depleted salinization.

\section{References}

[1] WP Kelley, SM Brown, and GF Liebig Jr. "Chemical effects of saline irrigation water on soils". In: Soil science 49.2 (1940), pp. 95-108. 
[2] LV Wilcox, George Y Blair, and CA Bower. "Effect of bicarbonate on suitability of water for irrigation". In: Soil Science 77.4 (1954), pp. 259266.

[3] F. M. Eaton. "Significance of carbonates in irrigation waters". In: Soil Science 69.2 (1950), pp. 123-134.

[4] USSL. Diagnosis and improvement of saline and alkali soils. US Government Printing Office, 1954.

[5] P. Rengasamy and A. Marchuk. "Cation ratio of soil structural stability (CROSS)". In: Soil Research 49.3 (2011), pp. 280-285.

[6] John David Hem. Study and interpretation of the chemical characteristics of natural water. Water Supply Paper 2254, Department of the Interior, US Geological Survey, 1985.

[7] P Rengasamy and ME Sumner. "Processes involved in sodic behaviour". In: ed. by ME Sumner and R Naidu. Oxford University Press, 1998, pp. 3550.

[8] JD Oster, G Sposito, and CJ Smith. "Accounting for potassium and magnesium in irrigation water quality assessment". In: California Agriculturd 70.2 (2016), pp. $71-76$.

[9] JD Rhoades et al. "Salts in Irrigation Drainage Waters: I. Effects of Irrigation Water Composition, Leaching Fraction, and Time of Year on the Salt Compositions of Irrigation Drainage Waters". In: Soil Science Society of America Journal 37.5 (1973), pp. 770-774.

[10] JD Oster and JD Rhoades. "Calculated drainage water compositions and salt burdens resulting from irrigation with river waters in the western United States 1". In: Journal of Environmental Quality 4.1 (1975), pp. 7379.

[11] JD Rhoades and SD Merrill. "Assessing the suitability of water for irrigation: theoretical and empirical approaches". In: FAO Soils Bulletin 9. Food and Agricultural Organization of the United Nations, 1976.

[12] L.E. Allison and R.C. Reeve. "Lysimeters for studying effects of salinity, leaching, and position of water table on plant growth". In: Soil Science 79.2 (1955), pp. 81-92.

[13] L. A. Hardie and H. P. Eugster. "The evolution of closed-basin brines". In: ed. by B. A. Morgan et al. Special Paper 3. Mineralogical Society of America, 1970, pp. 273-290.

[14] Harold C Helgeson et al. "Calculation of mass transfer in geochemical processes involving aqueous solutions". In: Geochimica et Cosmochimica Acta 34.5 (1970), pp. 569-592.

[15] JD Oster and BL McNeal. "Computation of Soil Solution Composition Variation with Water Content for Desaturated Soils 1". In: Soil Science Society of America Journal 35.3 (1971), pp. 436-442. 
[16] Šimůnek and Donald L Suarez. "Modeling of carbon dioxide transport and production in soil: 1. Model development". In: Water Resources Research 29.2 (1993), pp. 487-497.

[17] S Miyamoto. "Effects of Bicarbonate on Sodium Hazard of Irrigation Water: Alternative Formulation 1". In: Soil Science Society of America Journal 44.5 (1980), pp. 1079-1084.

[18] D. L. Suarez. "Relation Between $\mathrm{pH}_{\mathrm{c}}$ and Sodium Adsorption Ratio (SAR) and an Alternative Method of Estimating SAR of Soil or Drainage Waters". In: Soil Science Society of America Journal 45.3 (1981), pp. 469475 .

[19] H[arold] C Helgeson. "Evaluation of irreversible reactions in geochemical processes involving minerals and aqueous solutions-I. Thermodynamic relations". In: Geochimica et Cosmochimica Acta 32.8 (1968), pp. 853877.

[20] C. A. Bower, G. Ogata, and J. M. Tucker. "Sodium hazard of irrigation waters as influenced by leaching fraction and by precipitation or solution of calcium carbonate". In: Soil Science 106.1 (1968), pp. 29-34.

[21] Wilfred F Langelier. "The analytical control of anti-corrosion water treatment". In: Journal-American Water Works Association 28.10 (1936), pp. 15001521.

[22] R. S. Ayers and D. W. Westcot. Water quality for agriculture. Irrigation ans Drainage Paper 29, Food and Agriculture Organization of the United Nations Rome, 1976.

[23] R. S. Ayers and D. W. Westcot. Water quality for agriculture. Irrigation ans Drainage Paper 29, Food and Agriculture Organization of the United Nations Rome, 1985.

[24] J Šimůnek et al. "The HP2 program for HYDRUs (2D/3D): A coupled code for simulating two-dimensional variably-saturated water flow, heat transport, and biogeochemistry in porous media, version 1.0". In: PC Progress, Prague, Czech Republic (2012). 